\title{
Validation of a 2.5D CFD model for cylindrical gas-solids fluidized beds
}

\author{
Tingwen $\mathrm{Li}^{\mathrm{a}, \mathrm{b}, *}$
}

a National Energy Technology Laboratory, Morgantown, WV 26505, USA

b AECOM, Morgantown, WV 26505, USA

\begin{abstract}
The 2.5D model recently proposed by Li et al. (Li, T., Benyahia, S., Dietiker, J., Musser, J., and Sun, X., 2015. A 2.5D computational method to simulate cylindrical fluidized beds. Chemical Engineering Science. 123, 236-246) was validated for two cylindrical gas-solids bubbling fluidized bed systems. Different types of particles tested under various flow conditions were simulated using the traditional 2D model and the 2.5D model. Detailed comparison against the experimental measurements on solid concentration and velocity were conducted. Comparing to the traditional Cartesian 2D flow simulation, the 2.5D model yielded better agreement with the experimental data especially for the solid velocity prediction in the column wall region.
\end{abstract}

Key words: gas-solids fluidized bed, 2D flow assumption, MFIX, computational fluid dynamics, numerical simulation, validation

* Corresponding author at: National Energy Technology Laboratory,

Morgantown, WV 26505, USA. Tel.: 13042854538.

E-mail addresses: tingwen.li@contr.netl.doe.gov, litingwen@gmail.com (T. Li). 


\section{Introduction}

Gas-solids fluidized bed reactors are widely used in the chemical industries owing to their excellent gas-solids contact and favorable heat- and mass-transfer characteristics. Continuous efforts have been made during the past decades to gain a thorough understanding of the fundamentals of gas-solids fluidized beds using various tools. With the rapid development of high-performance computers, computational algorithms, and multiphase flow models, computational fluid dynamic (CFD) modeling has become an effective tool to help researchers better understand the complex flow hydrodynamics in fluidized beds. However, the computational cost of simulating gas-solids flows is extremely high due to inherent unsteady and highly coupled multi-scale characteristics that require highly resolved numerical grids and small time steps. Various methods have been introduced to reduce the computational cost and accelerate the simulations for gas-solid systems such as coarse grain method [1] and sub-grid models [2]. Specifically, to alleviate the computational cost of transient simulation of gas-solids fluidized beds, numerous two-dimensional (2D) numerical simulations of various fluidization regimes, e.g. bubbling, slugging, turbulent, and circulating fluidized beds have been reported in the literature.

In most applications, cylindrical columns are routinely used for the fluidized beds. Considering the symmetry in geometry and flow conditions of most cylindrical gas-solids fluidized beds, it is natural to make the axisymmetric assumption to reduce the computational cost. However, it has been generally realized that in the axisymmetric assumption the central axis behaves like a freeslip wall and prevents the gas-solids flow from crossing it [3-6]. Hence, high solids concentration and downward solids flow were often reported along the central axis of the bubbling fluidized 
bed when using the axisymmetric flow assumption. This is inconsistent with the experimental observation of the usually upward flow with low solids concentration in the central region. Due to the unphysical accumulation of solids along the central line, the axisymmetric flow assumption is rarely used in the unsteady flow simulation of fluidized beds. An alternative, the Cartesian 2D simulation of a vertical plane cutting along the central axis is commonly used in simulating the cylindrical gas-solids fluidized beds. The Cartesian 2D simulation breaks the symmetry constraint along the central axis in the axisymmetric assumption and predicts qualitatively more consistent results to the experimental observation.

Despite the wide applications of 2D Cartesian simulation for various gas-solids fluidization systems, it is generally acknowledged that there exist considerable differences between 2D and 3D simulations. The limitations of 2D Cartesian model comparing to the 3D simulation have been discussed by several authors in the literature [6-13]. All studies revealed significant quantitative differences between $2 \mathrm{D}$ and $3 \mathrm{D}$ simulations. The reported differences could be attributed to the inherent three dimensional flow structures in the gas-solids flow and the geometrical inconsistency of simplifying a cylinder to a Cartesian 2D plane. Consequently, a 2D simulation is recommended for qualitative evaluation and only a 3D modeling is recommended for quantitative predictions.

Recently, to overcome the geometrical inconsistency in the 2D simulation, a $2.5 \mathrm{D}$ model was recently proposed by Li et al. for simulating the cylindrical gas-solids fluidized beds operated in batch mode. The new model combined the Cartesian 2D assumption and the axisymmetric flow assumption followed the same idea by Sun and Gidaspow [14]. This new method has been 
tested for a small bubbling fluidized bed system for which various 2D and 3D simulations were conducted. Detailed comparison of the flow hydrodynamics were made after careful grid studies. Through comparison with highly resolved 3D simulation results, the 2.5D model produced improved results compared to the 2D Cartesian and 2D axisymmetric assumptions.

The objective of the current study is to validate the $2.5 \mathrm{D}$ model results against available experimental data for cylindrical gas-solids bubbling fluidized bed. For this purpose, both 2D and 2.5D simulations of two well documented experimental systems covering a wide range of operating conditions have been conducted. Numerical results are compared against the experimental data of solids concentration and solids velocity for validation.

\section{Model Description}

In this section, the 2.5D model proposed by Li et al. [15] is briefly reviewed. In the 2.5D model, a novel computational domain made of two wedges connected by a thin plate is proposed to combine the advantages of axisymmetric and 2D Cartesian simulations. The computational domain is schematically shown in Figure 1 . Two parameters define the computational domain of the $2.5 \mathrm{D}$ model, i.e. $L / R$, the ratio between the plate half width $L$ and the wedge radius $R$, and $\alpha$, the wedge angle. Here L/R is adjustable and determines the thickness of the plate, $\mathrm{H}$. By adjusting the ratio between $L$ and $R$, the simulation varies between axisymmetric and two dimensional. This approach attempts to impose flow symmetry in a cylindrical column by adopting the wedge-shape computational domain. At the same time, it allows the flow to pass through the central axis by incorporating the 2D Cartesian flow assumption in the central region. As L/R determines the compromise between axisymmetric and 2D flow assumptions, it is critical 
to choose an appropriate value for best model performance. On the other hand, the wedge angle, $\alpha$, has shown to have negligible effect on the simulation results [15]. With a small angle of wedge the computational domain can be discretized by a single layer of cells which makes the computational cost the same as the 2D model.

Figure 1.

The 2.5D model has been implemented into the open-source code, Multiphase Flow with Interphase eXchanges (MFIX) 2015-1 release, developed at the National Energy Technology Laboratory (NETL). In MFIX, the multi-fluid, Eulerian-Eulerian approach is used, with each phase treated as an interpenetrating continuum. Mass and momentum conservation equations are solved for the gas and solids (particulate) phases, with appropriate closure relations [16-17]. The model equations solved in the current study are briefly summarized in Table 1.

Table 1

\section{Model Validation}

As suggested by Grace and Taghpour [18], validation should cover a wide range of fluidization regimes and operating conditions to fully evaluate the performance of the CFD model. In the current study, we focused on validation of the $2.5 \mathrm{D}$ model for the bubbling fluidization regime against experimental data from the literature. To make sure the validation study is 
comprehensive, two different experimental setups using different particles and various flow conditions were considered.

\subsection{Experiments of Makkawi et al. [19]}

Makkawi et al. [19] reported the solids volume fraction distribution in a freely bubbling bed measured using the electrical capacitance tomography (ECT). In their experimental facility, the cold fluidization tests were carried out in a cast acrylic cylindrical column with internal diameter of $13.8 \mathrm{~cm}$. Air at ambient conditions was introduced through a perforated distributor located at the bottom of the column to fluidize the bed material. Two types of particles with mean diameters of $350 \mu \mathrm{m}$ and $125 \mu \mathrm{m}$ were tested which can be categorized as group B and group A/B respectively according to Geldart's classification. Different gas velocities were tested for both types of particles. The experiment data were collected for a period of 50 seconds using ECT at 100 frames per second.

In the current validation study, fluidizations of both types of particles were simulated. The particle properties and operating conditions simulated are summarized in Table 2 . The simple rectangle domain was used for both $2 \mathrm{D}$ and $2.5 \mathrm{D}$ numerical simulations. The $2.5 \mathrm{D}$ simulation accounted for the variation in the third dimension as illustrated in Figure 1. The system was initialized with a static bed height of $20 \mathrm{~cm}$ according to the experimental tests. Gas flow was then introduced through the bottom to fluidize the bed. Unsteady simulations were conducted with the transient results saved for post-processing and analysis. 
Table 2.

The boundary conditions used in the simulations are summarized as follows. At the top boundary, a constant pressure was assumed and particles are free to leave the system. For the bottom distributor, a uniform gas velocity is specified, with no solids entering the domain. For the gas phase, a no-slip wall boundary condition was used. Different wall boundary conditions for the solids phase were investigated which will be discussed later.

The simulations were conducted for 250 s and the first 10 s was excluded in analysis to avoid the startup effect. The longer simulation time compared to the time for experimental measurement was intent to achieve symmetric results to facilitate comparison with experimental data which demonstrated slight asymmetric flow behavior. This should help eliminate the discrepancy between simulation and experimental data caused by comparing different radial directions.

\section{Grid convergence}

A grid resolution of $40 \times 160$ was used to discretize the computational domain for the coarse particles with a diameter of $350 \mu \mathrm{m}$. This led to a grid size of about 12-particle-diameter which is believed to be sufficient to achieve grid independent results based on our previous experiences $[12,20]$. To confirm the grid independence, a fine grid simulation using the grid resolution of 60 $X 240$ was conducted for both $2 \mathrm{D}$ and 2.5D simulations. Figure 2 compares the radial profiles of mean voidage and solid vertical velocity predicted by the coarse and fine grids for the case with a superficial gas velocity of $80 \mathrm{~cm} / \mathrm{s}$. The radial profiles were obtained through averaging between 14.3 and $18.1 \mathrm{~cm}$ above the distributor according to the experimental measurement. 
As can be seen from the comparison, the excellent consistency between coarse and fine grid results suggests good grid convergence. In the following analyses, the grid resolution of $40 \times 160$ was used for this type of particles.

Figure 2.

\section{Effect of L/R}

A small section of plate to connect two wedges was recommended to maintain the geometrical similarity between the simulated domain and the cylinder fluidized bed. However, as demonstrated by Li et al. [15], it is critical to choose an appropriate value for L/R to achieve the best compromise between axisymmetric and 2D flow assumptions. For this purpose, a parametric study for $L / R$ has been conducted for the case with a superficial gas velocity of 80 $\mathrm{cm} / \mathrm{s}$. The radial profiles of mean voidage and solids vertical velocity averaged between 14.3 and $18.1 \mathrm{~cm}$ above the distributor are compared in Figure 3. The experimental data measured by ECT is presented as reference. The experimental data has been flipped and shown with the original ones to avoid the asymmetric flow behavior in the measurement. As can be seen from Figure $3(a)$, there exist a significant solids accumulation in the central region for $L / R=0.1$. As the values of $L / R$ increases, the solids accumulation there tends to disappear and the voidage profiles for $L / R$ of $0.4,0.5$ and 0.6 show good resemblance to that of $2 \mathrm{D}$ simulation. This is consistent to the fact that the $2.5 \mathrm{D}$ model assumption shifts gradually from axisymmetric to two-dimensional as L/R increases from 0 to 1 . As far as the radial voidage profile is concerned, results of high $L / R^{\prime}$ s of $2.5 \mathrm{D}$ runs and the $2 \mathrm{D}$ simulation both show reasonable agreement to the experimental data. However, there exist considerable differences between the solids velocity 
profiles predicted by $2.5 \mathrm{D}$ and $2 \mathrm{D}$ models. It can be seen from Figure $3(\mathrm{~b})$ that the solids velocity profiles are very sensitive to the value of $L / R$. As $L / R$ increases, magnitudes of the upward velocity in the central region and downward velocity close to the walls increase. The $2 \mathrm{D}$ simulation, which corresponds to the $2.5 \mathrm{D}$ model with $\mathrm{L} / \mathrm{R}=1$, predicted the strongest upflow in the central region and downflow close to the walls which suggest more vigorous internal solids circulation than the other 2.5D simulations. For the results presented in the following paragraphs, constant value of 0.5 for L/R was used for all 2.5D simulations.

Figure 3.

\section{Effect of Granular Temperature Model}

Instead of solving the partial differential equation (PDE) for granular temperature listed in Table 1, an algebraic form of granular temperature [16] can be used by assuming an equilibrium between its generation and dissipation in the simulations. The simplified algebraic expression for granular temperature has been used in many numerical simulations to save the computational cost while still maintaining reasonable accuracy [21-23]. Detailed numerical implementation of the algebraic model for granular temperature can be found in [16-17]. It is important to study the impact of simplifying the complicated PDE to an algebraic expression especially in the new model approach. Figure 4 compares the predictions of both $2 \mathrm{D}$ and $2.5 \mathrm{D}$ simulations using different forms of granular temperature. For the 2.5D simulation, the value of 0.5 for $L / R$ was used. As can be seen from the comparison, the choice of different forms of granular temperature has almost no impact on the voidage profiles. However, it does affect the solids velocity slightly. The PDE for granular temperature leads to slightly higher solids velocity in 
the center and lower solids velocity close to the walls. The $2.5 \mathrm{D}$ model shows somewhat more sensitivity to the choice of granular temperature equation than the 2D model. For the results presented in Figure 4, the no-slip wall boundary condition for the solid phase was used. Similar comparison was conducted for the simulations using a free-slip wall boundary condition which is not shown here for brevity. Overall, the algebraic form of granular temperature has been demonstrated a valid assumption for the current system which is consistent to the finding reported in the literature $[21,24]$. For the best model performance, the full partial differential equation for the granular temperature was solved in the rest simulations.

Figure 4.

\section{Effect of Wall Boundary Condition}

It has been reported that the boundary conditions for the solids phase has a significant impact on the flow hydrodynamics predicted by CFD modeling, especially for the lab scale experimental systems [10, 20, 25-27]. Generally, it is believed that a partial-slip boundary condition is most realistic for the solids phase. The effect of solids phase wall boundary conditions has been investigated for the current system. Both free-slip wall and no-slip wall boundary conditions as well as the partial-slip boundary condition were tested. For the partial-slip boundary condition, the model by Johnson and Jackson [28] was used. In Johnson and Jackson boundary condition, a specularity coefficient is needed to characterize the tangential momentum transfer during particle-wall collisions. Since it is difficult to measure this parameter experimentally, the semitheoretical expression for the specularity coefficient developed by Li and Benyahia [29] was 
used. In this method, the specularity coefficient is automatically determined based on the flow conditions and physical properties for each computational cell adjacent to the wall [30]. For all simulations, the no-slip wall boundary condition was used for the gas phase.

Figure 5 presents the radial profiles of voidage and solids velocity predicted by different wall boundary conditions for both $2 \mathrm{D}$ and $2.5 \mathrm{D}$ models. There exist great discrepancy between the results predicted by free-slip and no-slip wall boundary conditions for both voidage and solids velocity. The free-slip wall leads to very strong solids downward flow and high solids concentration along the wall. While the no-slip and partial-slip wall boundary conditions predict similar radial solid distribution with the densest region slightly away from the wall and slight difference in the near wall region. There exist certain differences in the solids velocity profiles mainly in the central and wall regions between no-slip and partial-slip wall simulations. As far as the experimental data is concerned, the results by no-slip and partial-slip wall boundary conditions show better agreement than that by the free-slip wall boundary condition. The results here suggest a free-slip wall boundary condition should be carefully used for a bubbling fluidized bed system which is consistent to the finding reported in the literature.

Figure 5.

\section{Validation against different operating conditions}

Through the above analyses, the optimum model parameters are determined for the validation study. For the rest of validations, the PDE for granular temperature was solved and the partialslip wall boundary condition was used for the solids phase. In addition, the value of 0.5 for L/R 
was used in all 2.5D simulations. Three superficial gas velocities of $0.26,0.54$ and $0.8 \mathrm{~m} / \mathrm{s}$ were simulated for the large particles with size of $350 \mu \mathrm{m}$ with the results shown in Figure 6. Overall, both $2 \mathrm{D}$ and 2.5D predictions yield reasonable agreement to the experimental measurements of voidage profile. However, there do exist considerable differences between the radial profiles of vertical solids velocity which characterizes the internal circulation of solids inside the system. The magnitude of solids vertical velocity predicted by the $2.5 \mathrm{D}$ simulations is consistently lower in both central region and wall region comparing to the $2 \mathrm{D}$ simulations which suggest a stronger solids circulation predicted by the $2 \mathrm{D}$ simulations. The difference is very significant for low superficial gas velocity and become less obvious for high superficial gas velocity.

Figure 6.

Similar simulations have been conducted for the fine particles with a diameter of $125 \mu \mathrm{m}$. For the numerical simulation of fine particles, a finer grid resolution of $120 \times 480$ was used which yielded a grid size of $1.15 \times 1.67 \mathrm{~mm}$. A further grid refinement to $240 \times 480$ was carried out which confirmed the grid independence. The same model settings were used in the simulations, i.e. PDE for granular temperature, partial-slip wall boundary condition and $L / R=0.5$ for the $2.5 \mathrm{D}$ simulations. Two superficial gas velocities of 0.26 and $0.40 \mathrm{~m} / \mathrm{s}$ were simulated. The radial profiles of voidage and solids velocity averaged between 14.3 and $18.1 \mathrm{~cm}$ above the distributor are shown in Figure 7. Similar radial voidage profiles are predicted by both $2 \mathrm{D}$ and $2.5 \mathrm{D}$ simulations and no distinct differences can be observed. There still exist differences between 2D and 2.5D simulation especially for the solids velocity as the 2D model tends to predict stronger upflow in center and downflow close to the walls. Compared to the experimental data, the 
voidage in most region of the column was over-predicted by both $2 \mathrm{D}$ and $2.5 \mathrm{D}$ simulations. It is not clear the reason for the over-prediction.

Figure 7.

\subsection{Experiments of Laverman et al. [31]}

In the above validation study, it was shown that both 2D and 2.5D models are capable of predicting reasonable flow behavior with respect to the experimental measurements of radial voidage profile. However, there exist considerable differences in the solids velocity profiles between these two models. Hence, it is important to compare against the experimental measurement for the solids velocity to further validate the $2.5 \mathrm{D}$ model.

The experimental setup by Laverman et al. [31] was chosen to validate the model prediction of solids movement inside the fluidized bed. The experimental column was constructed of PVC and had an outer diameter of $0.314 \mathrm{~m}$ and an inner diameter of $0.306 \mathrm{~m}$. The bed was filled with either glass beads with a diameter of $400-600 \mu \mathrm{m}$ or with linear low density polyethylene (LLDPE) particles with a diameter of 1000-1300 $\mu \mathrm{m}$. The non-invasive positron emission particle tracking (PEPT) was used to measure the solids movement within 2.5 to 3 hours. Mean solids velocity was obtained for each particle under different operating conditions, i.e. superficial gas velocity and bed ratio. 
In the current study, the glass beads were simulated by assuming a mean particle size of $500 \mu \mathrm{m}$. The physical properties and numerical parameters used in the simulations are summarized in Table 3. Two static bed heights of 30 and $45 \mathrm{~cm}$, corresponding to bed ratios of 1 and 1.5 , and three superficial gas velocities of 27,45 and 63 , which correspond to $1.5,2.5$ and 3.5 times the minimum fluidization velocity, were simulated. A grid with resolution of 90X450 was used for the computational domain of $30.6 \times 150 \mathrm{~cm}$. The grid size is about 6 particle diameter which is believed sufficient $[20,32]$. Similar model settings to the previous case were used for the simulation. The PDE for granular temperature was solved and the partial-slip wall boundary condition for the solids phase was used. Both 2D and 2.5D simulations were conducted for validation against the measurement. For the $2.5 \mathrm{D}$ simulation, $\mathrm{L} / \mathrm{R}$ of 0.5 was used. All simulations were conducted for $100 \mathrm{~s}$ physical time and the last $90 \mathrm{~s}$ results were analyzed.

Table 3.

In the experiments, the position of the radioactive tracer particle was tracked by the detectors during a long period of time around $10000 \mathrm{~s}$. The particle velocity was calculated from the time history of tracer particle position and time-averaged solid velocity profiles were obtained finally. It should be noted that mean solid velocity obtained through this approach differs from the simple time average velocity through numerical simulation due to the preferential presence of the tracer particle in the high solid concentration region. To be consistent to the experimental measurement, the weighted mean solids velocity is calculated as [33]

$$
\bar{V}_{s}=\frac{\left\langle\varepsilon_{s} V_{s}\right\rangle}{\left\langle\varepsilon_{s}\right\rangle}
$$


Where the <> indicate time average. Equation (1) becomes simple time averaging when the flow is homogenous. Figure 8 compares the radial profiles of solid vertical velocity at different elevations calculated by the weighted time average according to equation (1) and simple time average. Considerable difference can be observed especially in the central region of the upper bed where the presence of vigorous bubbles leads to strong heterogeneous flow structures.

Figure 8.

Radial profiles of mean voidage and solids vertical velocity at various elevations above the distributor for different superficial gas velocities are shown in Figure 9 and Figure 10 for the static bed heights of 30 and $45 \mathrm{~cm}$, respectively. The experimental data measured from PEPT are shown for comparison. Good symmetric in the experimental data has been assumed and confirmed by the repeated tests by Laverman et al. [31]. In the figures, the experimental data has been mirrored to compare to the numerical results predicted along the diameter. For both bed heights with different superficial gas velocities, the predicted voidage profiles by both 2D and 2.5D simulations at various elevations are similar which is consistent to the simulation results shown above. However, some distinctions can be observed in the radial voldiage profiles at the height of $0.11 \mathrm{~cm}$ for superficial gas velocities of $2.5 \mathrm{Umf}$ and $3.5 \mathrm{Umf}$. The 2.5D simulations predicted higher voidage in the near wall region which indicates the preferential path for bubbles to move up. This behavior is less obvious from the 2D simulations. Similar conclusion can be obtained from the solid velocity profiles. Consistent with the previous cases, strong discrepancies in solids velocity profiles in the central and near wall regions can be observed between $2 \mathrm{D}$ and $2.5 \mathrm{D}$ simulations. The $2.5 \mathrm{D}$ simulations consistently predict lower 
solids velocity magnitudes in both central and wall regions, except for the case with low superficial gas velocity of $1.5 \mathrm{Umf}$ in which the solids circulation pattern is quite different from the rest. Comparing to the experimental measurements of solids velocity profiles, the $2.5 \mathrm{D}$ simulation results show considerable improvement over the 2D simulation results, especially in the central and wall regions. Overall, the agreement between simulation results and experimental measurements are reasonably well.

Figure 9.

Figure 10.

\section{Further Discussion}

As indicated by Li et al. [15], a small value is preferential to maintain a good geometrical similarity to the real cylindrical system. In this study, a high value of 0.5 for L/R was used for most cases which introduced considerable discrepancy from the axi-symmetry in the cylindrical fluidized beds. According to the parametric study shown in Figure 3, low L/R values tend to predict high solids accumulation and low solids velocity in the center. Based on the sensitivity studies of different fluidized bed systems in the current study and Li et al. [15], the value of L/R in the range of $0.3^{\sim} 0.5$ works reasonably for the $2.5 \mathrm{D}$ model. To be conservative, a high value around 0.5 is recommended which still yield considerable improvement over the 2D simulation as shown in the current study. 
The current study confirmed that the new model improves the numerical predictions mainly in the solids velocity comparing to the old $2 \mathrm{D}$ model as far as the experimental measurements are concerned. Solids movement is closely related to the mixing inside the reactor hence it has a significant impact on the reactor performance. It is crucial for the CFD simulation to predict the correct solids motion in addition to solids distribution. It should be noted the fluidized bed modeling is sensitive to many model parameters such as drag correlation [34-36], frictional stress model [37, 38], and specularity coefficient for solid wall boundary condition [10, 20, 25-27] In the current validation exercise, no much effort has been spent on the drag correlation and frictional stress model and the same physical models are used for both 2D and 2.5D simulations. Hence, the results might be further improved by conducting comprehensive evaluation of the available models.

The current validation study indicated the $2.5 \mathrm{D}$ simulation improves quantitative agreement with the experimental data comparing to the widely used 2D simulation. It should be noted that the computational cost are essentially the same for $2 \mathrm{D}$ and $2.5 \mathrm{D}$ simulations. Comparing to the 2D simulation, the new model improves the geometrical similarity between the computational domain and the cylindrical column. As indicated before, the reason for the discrepancy between 2D and 3D simulations is two-fold: the geometrical inconsistency of simplifying a cylinder to a Cartesian 2D plane and the inherent three dimensional flow structures in gas-solids flows. The 2.5D model somehow overcomes the first issue by combining axisymmetric and 2D plane assumptions. However, the second issue persists. To fully resolve all these issues, a 3D simulation is always preferential when possible. 


\section{Conclusion}

In the current validation study, two different experimental systems, three types of particles under different operating conditions with a total of ten tests were considered. During the validation exercise, a careful sensitivity study was conducted for the grid resolution, wall boundary condition and other model parameter to identify the optimum combination of model parameters. Numerical results of both 2D and the recently proposed 2.5D models were compared to the experimental data of solids distribution and velocity. Both modeling approaches yielded good qualitative and reasonable quantitative agreement to the experimental measurements. The 2.5D model predicted similar solids concentration profiles and considerable different solids velocity profiles mainly in the wall region compared to those by the 2D model. The validation study clearly demonstrated the improved quantitative agreement to the experimental data by the newly proposed $2.5 \mathrm{D}$ model over the traditionally used $2 \mathrm{D}$ model.

\section{Acknowledgement}

This technical effort was performed in support of the U.S. Department of Energy, Office of Fossil Energy's Carbon Capture Simulation Initiative (CCSI) through the National Energy Technology Laboratory under the RES contract DE-FE0004000.

\section{Disclaimer}

This report was prepared as an account of work sponsored by an agency of the United States Government. Neither the United States Government nor any agency thereof, nor any of their employees, makes any warranty, express or implied, or assumes any legal liability or 
responsibility for the accuracy, completeness, or usefulness of any information, apparatus, product, or process disclosed, or represents that its use would not infringe privately owned rights. Reference herein to any specific commercial product, process, or service by trade name, trademark, manufacturer, or otherwise does not necessarily constitute or imply its endorsement, recommendation, or favoring by the United States Government or any agency thereof. The views and opinions of authors expressed herein do not necessarily state or reflect those of the United States Government or any agency thereof.

\section{Reference}

[1] M. Sakai, S. Koshizuka, Large-scale discrete element modeling in pneumatic conveying. Chemical Engineering Science. 64 (2009) 533-539.

[2] Y. Igci, S. Sundaresan, Constitutive models for filtered two-fluid models of fluidized gasparticle flows. Industrial \& Engineering Chemistry Research. 50 (2011) 13190-13201.

[3] C.C. Pain, S. Mansoorzadeh, C.R.E. deOliveira, A study of bubbling and slugging fluidised beds using the two-fluid granular temperature model. Internatioanl Journal of Multiphase Flow. 27 (2001) 527-551.

[4] L. Cabezas-Gomez, F.E. Milioli, Numerical study on the influence of various physical parameters over the gas-solid two-phase flow in the 2D riser of a circulating fluidized bed. Powder Technology. 132 (2003) 216-225.

[5] N. Reuge, L. Cadoret, C. Coufort-Saudejaud, S. Pannala, M. Syamlal, B. Caussat, Multifluid Eulerian modeling of dense gas-solids fluidized bed hydrodynamics: Influence of the dissipation parameters. Chemical Engineering Science. 63 (2008) 5540-5551. 
[6] N. Xie, F. Battaglia, S. Pannala, Effects of using two- versus three-dimensional computational modeling of fluidized beds - Part I, hydrodynamics. Powder Technology. 182 (2008) 1-13.

[7] N. Xie, F. Battaglia, S. Pannala, Effects of using two- versus three-dimensional computational modeling of fluidized beds: Part II, budget analysis. Powder Technology. 182 (2008) 14-24.

[8] L. Cammarata, P. Lettieri, G.D.M. Micale, D. Colman, 2D and 3D CFD simulations of bubbling fluidized beds using Eulerian-Eulerian models. International Journal of Chemical Reactor Engineering. A48 (2003) 1.

[9] E. Peirano, V. Delloume, B. Leckner, Two- or three-dimensional simulations of turbulent gassolid flows applied to fluidization. Chemical Engineering Science. 56 (2001)4787-4799.

[10] T. Li, Y. Zhang, J.R. Grace, X. Bi, Numerical investigation of gas mixing in gas-solid fluidized beds. AIChE Journal. 56 (2010) 2280-2296.

[11] S. Cloete, S.T. Johansen, S. Amini, Investigation into the effect of simulating a 3D cylindrical fluidized bed reactor on a 2D plane. Powder Technology. 239 (2013) 21-35.

[12] T. Li, A. Gel, S. Pannala, M. Shahnam, M. Syamlal, CFD simulations of circulating fluidized bed risers, Part I: grid study. Powder Technology 254 (2014) 170-180.

[13] T. Li, S. Pannala, M. Shahnam, CFD simulations of circulating fluidized bed risers, Part II: evaluation of differences between 2D and 3D simulations. Powder Technology. 254 (2014) 115124.

[14] B. Sun, D. Gidaspow, Computation of circulating fluidized-bed riser flow for the Fluidization VIII benchmark test. Industrial \& Engineering Chemistry Research. 38 (1999) 787-792. 
[15] T. Li, S. Benyahia, J. Dietiker, J. Musser, X. Sun, A 2.5D computational method to simulate cylindrical fluidized beds. Chemical Engineering Science. 123 (2015) 236-246.

[16] M. Syamlal, W. Rogers, T.J. O'Brien, MFIX documentation: Theory guide. Morgantown: U.S. Department of Energy (DOE), Morgantown Energy Technology Center, 1993.

[17] S. Benyahia, M. Syamlal, T.J. O'Brien, Summary of MFIX Equations.

https://mfix.netl.doe.gov/documentation/MFIXEquations2012-1.pdf.

[18] J.R. Grace, F. Taghipour, Verification and Validation of CFD Models and Dynamic Similarity for Fluidized Beds. Powder Technology. 139 (2004) 99-110.

[19] Y.T. Makkawi, P.C. Wright, R. Ocone, The effect of friction and inter-particle cohesive forces on the hydrodynamics of gas-solid flow: A comparative analysis of theoretical predictions and experiments. Powder Technology. 163 (2006) 69-79.

[20] T. Li, Y. Zhang, J.R. Grace, X. Bi, Study of wall boundary condition in numerical simulations of 2D bubbling fluidized beds. Powder Technology. 203 (2010) 447-457.

[21] B.G.M. van Wachem, J.C. Schouten, C.M. van den Bleek, Comparative analysis of CFD models of dense gas-solid systems. AIChE Journal. 47 (2001) 1035-1051.

[22] T. Li, C. Guenther, A CFD study of gas-solids jet in a riser flow. AIChE Journal. 58 (2012) 756769.

[23] T. Li, J. Dietiker, M. Shahnam, MFIX simulation of NETL/PSRI Challenge Problem of circulating fluidized bed. Chemical Engineering Science. 84 (2012) 746-760. 
[24] A.T. Mineto, M.P. de Souza Braun, H.A. Navarro, L. Cabezas-Gómez, Influence of the granular temperature in the numerical simulation of gas-solid flow in a bubbling fluidized bed. Chemical Engineering Communications. 201 (2014) 1003-1020.

[25] X. Lan, C. Xu, J. Gao, M. Al-Dahhan, Influence of solid-phase wall boundary condition on CFD simulation of spouted beds. Chemical Engineering Science. 69 (2012) 419-430.

[26] C. Loha, H. Chattopadhyay, P.K. Chatterjee, Euler-Euler CFD modeling of fluidized bed: Influence of specularity coefficient on hydrodynamic behavior. Particuology. 11 (2013) 673-680. [27] H. Zhong, J. Gao, C. Xu, X. Lan, CFD modeling the hydrodynamics of binary particle mixtures in bubbling fluidized beds: Effect of wall boundary condition. Powder Technology. 230 (2012) 232-240.

[28] P.C. Johnson, R. Jackson, Frictional collisional constitutive relations for antigranulocytesmaterials, with application to plane shearing. Journal of Fluid Mechanics. 176 (1987) 67-93.

[29] T. Li, S. Benyahia, Revisiting Johnson and Jackson boundary conditions for granular flows. AIChE Journal. 58 (2012) 2058-2068.

[30] T. Li, S. Benyahia, Evaluation of wall boundary condition parameters for gas-solids fluidizedbed simulations. AIChE Journal. 59 (2013) 3624-3632.

[31] J.A. Laverman, X. Fan, A. Ingram, M. van Sint Annaland, D.J. Parker, J.P.K. Seville, J.A.M. Kuipers, Experimental study on the influence of bed material on the scaling of solids circulation patterns in 3D bubbling gas-solid fluidized beds of glass and polyethylene using positron emission particle tracking. Powder Technology. 224 (2012) 297-305. 
[32] S. Cloete, S.T. Johansen, S. Amini, Grid independence behaviour of fluidized bed reactor simulations using the Two Fluid Model: Effect of particle size. Powder Technology. 269 (2015) $153-165$.

[33] V.K., Verma, N.G. Deen, J.T. Padding, J.A.M. Kuipers, Two-fluid modeling of threedimensional cylindrical gas-solid fluidized beds using the kinetic theory of granular flow. Chemical Engineering Science. 102 (2013) 227-245.

[34] W. Du, X. Bao, J. Xu, W. Wei, Computational fluid dynamics (CFD) modeling of spouted bed: Assessment of drag coefficient correlations. Chemical Engineering Science. 61 (2006) 1401-1420.

[35] B. Estejab, F. Battaglia, A CFD Study of Existing Drag Models for Geldart A Particles in Bubbling Fluidized Beds, 14th International Symposium on Numerical Methods for Multiphase Flow. FEDSM2014-21134.

[36] C. Loha, H. Chattopadhyay, P.K. Chatterjee, Assessment of drag models in simulating bubbling fluidized bed hydrodynamics. Chemical Engineering Science. 75 (2012) 400-407. [37] A. Passalacqua, L.A. Marmo, A critical comparison of frictional stress models applied to the simulation of bubbling fluidized beds. Chemical Engineering Science. 64 (2009) 2795-2806.

[38] M. Farzaneh, A. Almstedt, F. Johnsson, D. Pallarès, S. Sasic, The crucial role of frictional stress models for simulation of bubbling fluidized beds. Powder Technology. 270 (2015) 68-82. 
Table 1. Summary of MFIX equations

A. Governing equations

(a) Continuity equations

Gas phase $\quad \frac{\partial}{\partial t}\left(\varepsilon_{g} \rho_{g}\right)+\nabla \cdot\left(\varepsilon_{g} \rho_{g} V_{g}\right)=0$

Solids phase $\quad \frac{\partial}{\partial t}\left(\varepsilon_{p} \rho_{p}\right)+\nabla \cdot\left(\varepsilon_{p} \rho_{p} \vec{V}_{p}\right)=0$

(b) Momentum equations

Gas phase $\quad \frac{\partial}{\partial t}\left(\varepsilon_{g} \rho_{g} \vec{V}_{g}\right)+\nabla \cdot\left(\varepsilon_{g} \rho_{g} \vec{V}_{g} \vec{V}_{g}\right)=\nabla \cdot \overline{\bar{\tau}}_{g}-\varepsilon_{g} \nabla P+\varepsilon_{g} \rho_{g} g-I_{g}$

Solids phase $\frac{\partial}{\partial t}\left(\varepsilon_{p} \rho_{p} \vec{V}_{p}\right)+\nabla \cdot\left(\varepsilon_{p} \rho_{p} \vec{V}_{p} \vec{V}_{p}\right)=\nabla \cdot \overline{\bar{\tau}}_{p}-\varepsilon_{p} \nabla P+\varepsilon_{p} \rho_{p} g+I_{g}$

B. Constitutive equations

(a) Gas stress tensor

$\overline{\bar{\tau}}_{g}=2 \mu_{g e} \overline{\bar{S}}_{g}$

$\overline{\bar{S}}_{g}=\frac{1}{2}\left(\nabla \vec{V}_{g}+\left(\nabla \vec{V}_{g}\right)^{T}\right)-\frac{1}{3}\left(\nabla \cdot \vec{V}_{g}\right) \overline{\bar{I}}$

(b) Solids stress tensor

$$
\begin{aligned}
& \overline{\bar{\tau}}_{p}=\left(-P_{s}+\eta \mu_{b} \nabla \cdot \vec{V}_{p}\right) \overline{\bar{I}}+2 \mu_{p} \overline{\bar{S}}_{p} \\
& \overline{\bar{S}}_{p}=\frac{1}{2}\left(\nabla \vec{V}_{p}+\left(\nabla \vec{V}_{p}\right)^{T}\right)-\frac{1}{3}\left(\nabla \cdot \vec{V}_{p}\right) \overline{\bar{I}} \\
& P_{s}=\varepsilon_{p} \rho_{p} \Theta_{p}\left[1+4 g_{0} \varepsilon_{p} \eta\right] \\
& \mu_{p}=\left(\frac{2+\alpha}{3}\right)\left[\frac{\mu_{p}^{*}}{g_{0} \eta(2-\eta)}\left(1+\frac{8}{5} \eta g_{0} \varepsilon_{p}\right)\left(1+\frac{8}{5} \eta(3 \eta-2) g_{0} \varepsilon_{p}\right)+\frac{3}{5} \eta \mu_{b}\right] \\
& \mu_{p}^{*}=\frac{\varepsilon_{p} \rho_{p} \Theta_{p} g_{0} \mu}{2 \varepsilon_{p} \rho_{p} \Theta_{p} g_{0}+\frac{2 \beta}{\varepsilon_{p} \rho_{p}}}
\end{aligned}
$$




$$
\begin{aligned}
& \mu=\frac{5}{96} \rho_{p} d_{p} \sqrt{\pi \Theta_{p}} \\
& \mu_{b}=\frac{256}{5 \pi} \mu \varepsilon_{p}^{2} g_{0} \\
& \eta=\frac{1+e}{2}
\end{aligned}
$$

(c) Frictional model

$$
\begin{aligned}
& P_{f}= \begin{cases}10^{24}\left(\varepsilon_{p}-\varepsilon_{p}^{*}\right)^{10} & \varepsilon_{p}>\varepsilon_{p}^{*} \\
0 & \varepsilon_{p} \leq \varepsilon_{p}^{*}\end{cases} \\
& \mu_{f}= \begin{cases}\min \left(\frac{P_{f} \sin (\phi)}{\sqrt{4 I_{2 D}},}, \mu_{f}^{\max }\right) & \varepsilon_{p}>\varepsilon_{p}^{*} \\
0 & \varepsilon_{p} \leq \varepsilon_{p}^{*}\end{cases} \\
& \mu_{f}^{\max }=100
\end{aligned}
$$

(d) Granular temperature

$$
\begin{aligned}
& \frac{3}{2}\left[\frac{\partial}{\partial t}\left(\varepsilon_{p} \rho_{p} \Theta_{p}\right)+\nabla \cdot\left(\varepsilon_{p} \rho_{p} \vec{V}_{p} \Theta_{p}\right)\right]=\overline{\bar{\tau}}_{p}: \vec{V}_{p}+\nabla \cdot\left(\kappa_{p, \Theta} \nabla \Theta_{p}\right)+\Pi_{g} \bar{p}_{p} \rho_{p} J_{p} \\
& \kappa_{p, \Theta}=\frac{\kappa_{p}^{*}}{g_{0}}\left[\left(1+\frac{12}{5} \eta \varepsilon_{p} g_{0}\right)\left(1+\frac{12}{5} \eta^{2}(4 \eta-3) \varepsilon_{p} g_{0}\right)+\frac{64}{25 \pi}(41-33 \eta) \eta^{2} \varepsilon_{p}^{2} g_{0}^{2}\right] \\
& \kappa_{p}^{*}=\frac{\rho_{p} \varepsilon_{p} g_{0} \Theta_{p} \kappa}{\rho_{p} \varepsilon_{p} g_{0} \Theta \Theta_{p}+\frac{6 \beta \kappa}{5 \rho_{p} \varepsilon_{p}}} \\
& \kappa=\frac{75 \rho_{p} d_{p} \sqrt{\pi \Theta_{p}}}{48 \eta(41-33 \eta)} \\
& J_{p}=\frac{48}{\sqrt{\pi}} \eta(1-\eta) \frac{\varepsilon_{p} g_{0} \Theta_{p}^{3 / 2}}{d_{p}} \\
& \prod_{g p}=-3 \beta \Theta \Theta_{p}+\frac{81 \varepsilon_{p} \mu_{g}^{2}\left|\vec{V}_{g}-\vec{V}_{p}\right|^{2}}{g_{0} d_{p}^{3} \rho_{p} \sqrt{\pi \Theta_{p}}}
\end{aligned}
$$




$$
\begin{aligned}
& \text { (e) Inter-phase momentum exchange } \\
& I_{g p}=\beta\left(\vec{V}_{g}-\vec{V}_{p}\right) \\
& \beta= \begin{cases}150 \frac{\varepsilon_{p}^{2} \mu_{g}}{\varepsilon_{g} d_{p}^{2}}+1.75 \frac{\varepsilon_{p} \rho_{g}\left|\vec{V}_{p}-\vec{V}_{g}\right|}{d_{p}} & \text { if } \varepsilon_{p}>0.2 \\
\frac{3}{4} C_{d} \varepsilon_{g}^{-2.65} \frac{\varepsilon_{p} \varepsilon_{g} \rho_{g}\left|\vec{V}_{p}-\vec{V}_{g}\right|}{d_{p}} & \text { if } \varepsilon_{p} \leq 0.2\end{cases} \\
& C_{d}= \begin{cases}\frac{24}{\operatorname{Re} \cdot \varepsilon_{g}}\left(1+0.15\left(\operatorname{Re} \cdot \varepsilon_{g}\right)^{0.687}\right) & \text { if Re } \varepsilon_{g}<1000 \\
0.44 & \text { if Re. } \varepsilon_{g} \geq 1000\end{cases} \\
& \operatorname{Re}=\frac{\rho_{g}\left|\vec{V}_{p}-\vec{V}_{g}\right| d_{p}}{\mu_{g}}
\end{aligned}
$$


Table 2. Summary of physical properties, operating conditions and numerical parameters used in the simulations.

\begin{tabular}{|l|l|l|l|}
\hline Parameter & Value & Parameter & Value \\
\hline Diameter $(\mathrm{cm})$ & 13.8 & Height $(\mathrm{cm})$ & 80 \\
\hline $\begin{array}{l}\text { Superficial gas } \\
\text { velocity }(\mathrm{cm} / \mathrm{s})\end{array}$ & $26,40,54,80$ & Bed inventory $(\mathrm{kg})$ & 0.8 \\
\hline Temperature $(\mathrm{K})$ & 297 & Pressure (atm) & 1 \\
\hline Gas viscosity (Pa.s) & $1.8 \mathrm{e}-5$ & $\begin{array}{l}\text { Gas molecular weight } \\
(\mathrm{kg} / \mathrm{kmol})\end{array}$ & 28.8 \\
\hline $\begin{array}{l}\text { Particle diameter } \\
(\mu \mathrm{m})\end{array}$ & 125,350 & $\begin{array}{l}\text { Particle density } \\
\left(\mathrm{kg} / \mathrm{m}^{3}\right)\end{array}$ & 2500 \\
\hline $\begin{array}{l}\text { Inter-particle } \\
\text { restitution coefficient }\end{array}$ & 0.95 & $\begin{array}{l}\text { Particle-wall } \\
\text { restitution coefficient }\end{array}$ & 0.8 \\
\hline $\begin{array}{l}\text { Angle of inter-particle } \\
\text { friction (deg) }\end{array}$ & 30 & $\begin{array}{l}\text { Particle-wall frictional } \\
\text { angle (deg) }\end{array}$ & 30 \\
\hline Packing limit & 0.65 & & \\
\hline
\end{tabular}


Table 3. Summary of physical properties and numerical parameters used in the simulations.

\begin{tabular}{|l|l|l|l|}
\hline Parameter & Value & Parameter & Value \\
\hline Diameter (cm) & 30.6 & Height $(\mathrm{cm})$ & 150 \\
\hline $\begin{array}{l}\text { Superficial gas } \\
\text { velocity }(\mathrm{cm} / \mathrm{s})\end{array}$ & $27,45,63$ & Static bed height $(\mathrm{cm})$ & 30,45 \\
\hline Temperature (K) & 297 & Pressure (atm) & 1 \\
\hline Gas viscosity (Pa.s) & $1.8 \mathrm{e}-5$ & $\begin{array}{l}\text { Gas molecular weight } \\
(\mathrm{kg} / \mathrm{kmol})\end{array}$ & 28.8 \\
\hline $\begin{array}{l}\text { Particle diameter } \\
(\mu \mathrm{m})\end{array}$ & 500 & $\begin{array}{l}\text { Particle density } \\
\left(\mathrm{kg} / \mathrm{m}^{3}\right)\end{array}$ & 2500 \\
\hline $\begin{array}{l}\text { Inter-particle } \\
\text { restitution coefficient }\end{array}$ & 0.95 & $\begin{array}{l}\text { Particle-wall } \\
\text { restitution coefficient }\end{array}$ & 0.8 \\
\hline $\begin{array}{l}\text { Angle of inter-particle } \\
\text { friction (deg) }\end{array}$ & 30 & $\begin{array}{l}\text { Particle-wall frictional } \\
\text { angle (deg) }\end{array}$ & 30 \\
\hline Packing limit & 0.62 & & \\
\hline
\end{tabular}




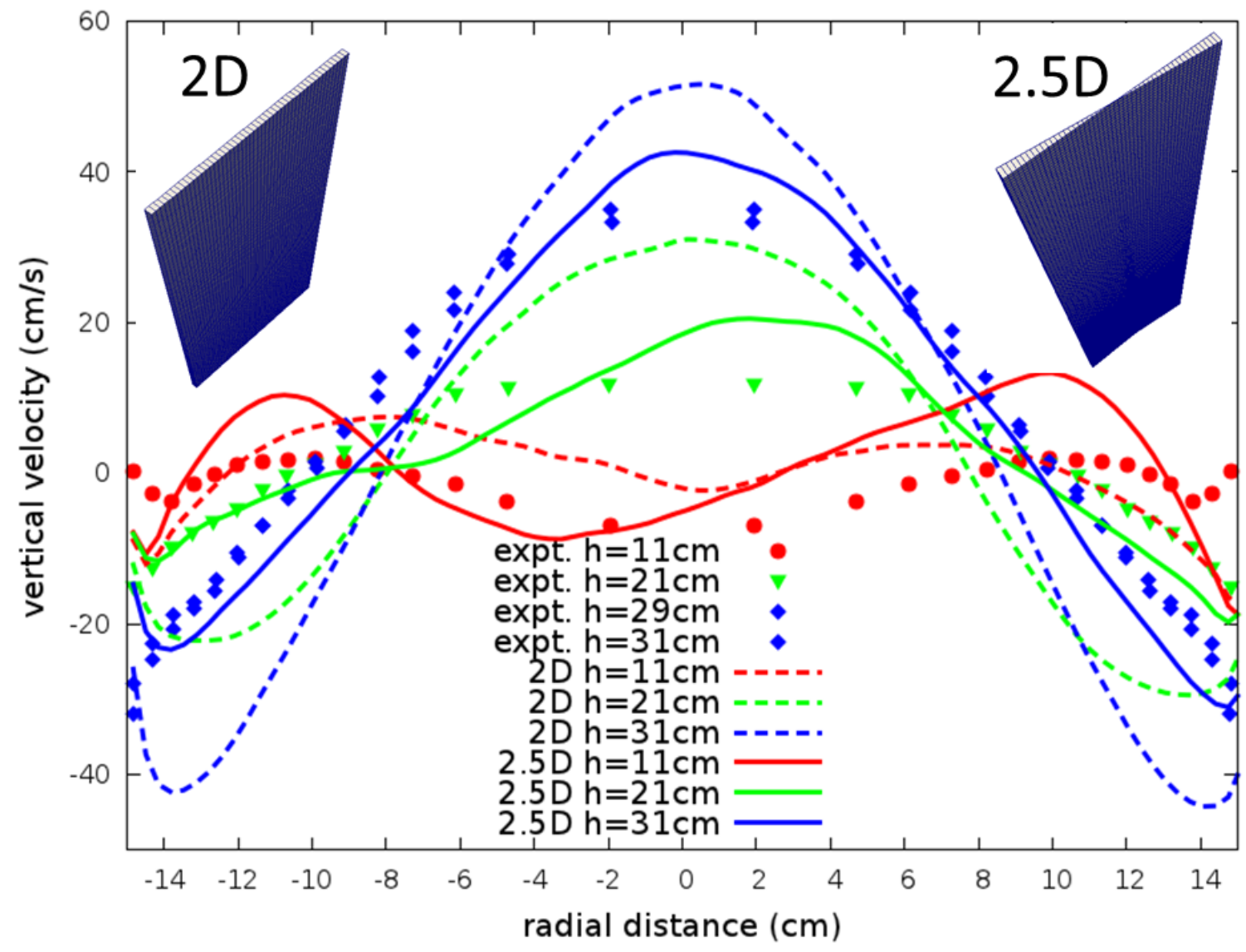

Graphical Abstract 


\section{List of Figures}

Figure 1. The computational domain of 2.5D model for fluidized bed simulations (Top view) .... 31 Figure 2. Time-averaged radial profiles averaged between $14.3-18.1 \mathrm{~cm}$ above the distributor predicted by coarse and fine grids (a) voidage, (b) vertical solid velocity ( $U g=80 \mathrm{~cm} / \mathrm{s}, \mathrm{d}_{\mathrm{p}}=350$ $\mu \mathrm{m})$.

Figure 3. Time-averaged radial profiles averaged between $14.3-18.1 \mathrm{~cm}$ above the distributor predicted by different L/Rs, (a) voidage, (b) vertical solid velocity $\left(\mathrm{Ug}=80 \mathrm{~cm} / \mathrm{s}, \mathrm{d}_{\mathrm{p}}=350 \mu \mathrm{m}\right) .32$ Figure 4. Time-averaged radial profiles averaged between $14.3-18.1 \mathrm{~cm}$ above the distributor predicted by algebraic and PDE granular temperature, (a) voidage, (b) vertical solid velocity (Ug $\left.=80 \mathrm{~cm} / \mathrm{s}, \mathrm{d}_{\mathrm{p}}=350 \mu \mathrm{m}\right)$.

Figure 5. Time-averaged radial profiles averaged between $14.3-18.1 \mathrm{~cm}$ above the distributor predicted by different types of wall boundary conditions for the solid phase $\left(U g=80 \mathrm{~cm} / \mathrm{s}, \mathrm{d}_{\mathrm{p}}=\right.$ $350 \mu \mathrm{m})$.

Figure 6. Time-averaged radial profiles averaged between $14.3-18.1 \mathrm{~cm}$ above the distributor for different superficial gas velocities, (a) $U g=26 \mathrm{~cm} / \mathrm{s}$, (b) $U g=54 \mathrm{~cm} / \mathrm{s}$, (c) $U g=80 \mathrm{~cm} / \mathrm{s}$. ( $\mathrm{d}_{\mathrm{p}}=$ $350 \mu \mathrm{m})$. 34

Figure 7. Time-averaged radial profiles averaged between $14.3-18.1 \mathrm{~cm}$ above the distributor for different superficial gas velocities, (a) $U g=26 \mathrm{~cm} / \mathrm{s}$, (b) $U g=40 \mathrm{~cm} / \mathrm{s}\left(\mathrm{d}_{\mathrm{p}}=125 \mu \mathrm{m}\right)$.

Figure 8. Comparison of mean solid vertical velocity calculated by weighted average and simple time average at different elevations ( $\mathrm{Ug}=3.5 \mathrm{Umf}$, Static bed height $=0.3 \mathrm{~m}$ ). 36

Figure 9. Radial profiles of solids velocity and voidage at different elevations (a) $\mathrm{Ug}=1.5 \mathrm{Umf}$, (b) $\mathrm{Ug}=2.5 \mathrm{Umf},(\mathrm{c}) \mathrm{Ug}=3.5 \mathrm{Umf}$ (Static bed height $=0.3 \mathrm{~m}$ )

Figure 10. Radial profiles of solids velocity and voidage at different elevations (a) Ug $=2.5 \mathrm{Umf}$,

(b) Ug = 3.5 Umf (Static bed height $=0.45 \mathrm{~m}$ ). 38 


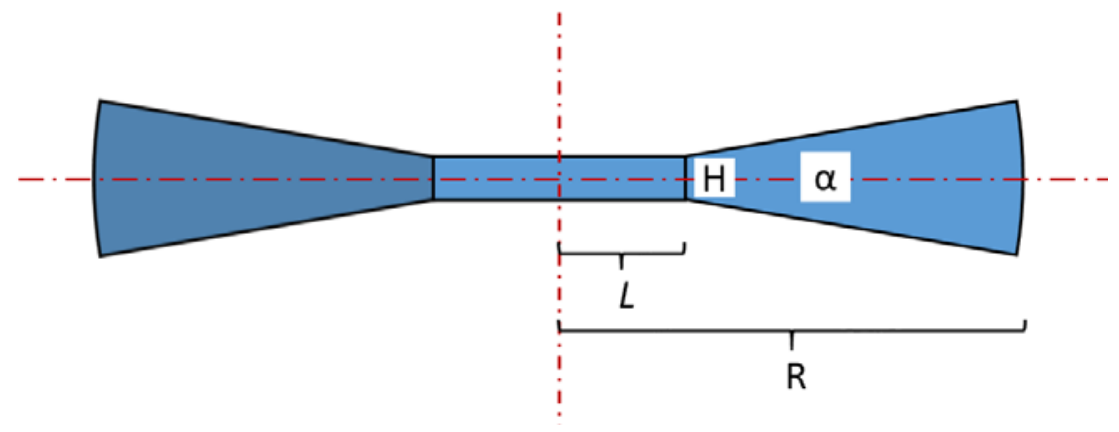

Figure 1. The computational domain of 2.5D model for fluidized bed simulations (Top view).

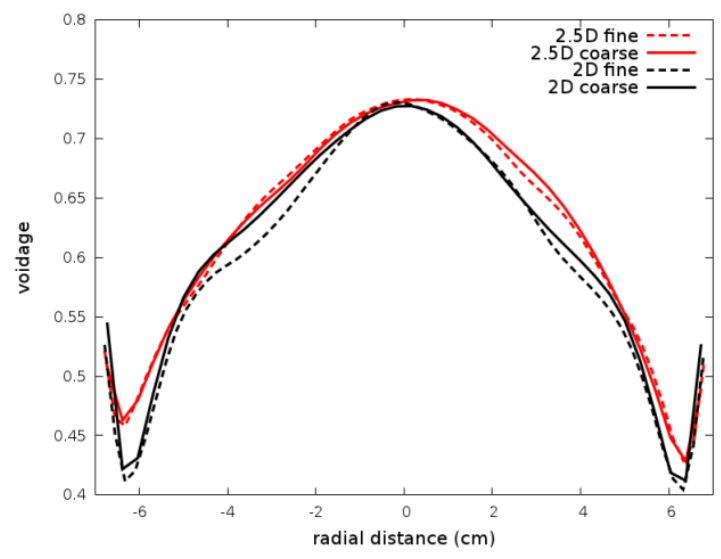

(a)

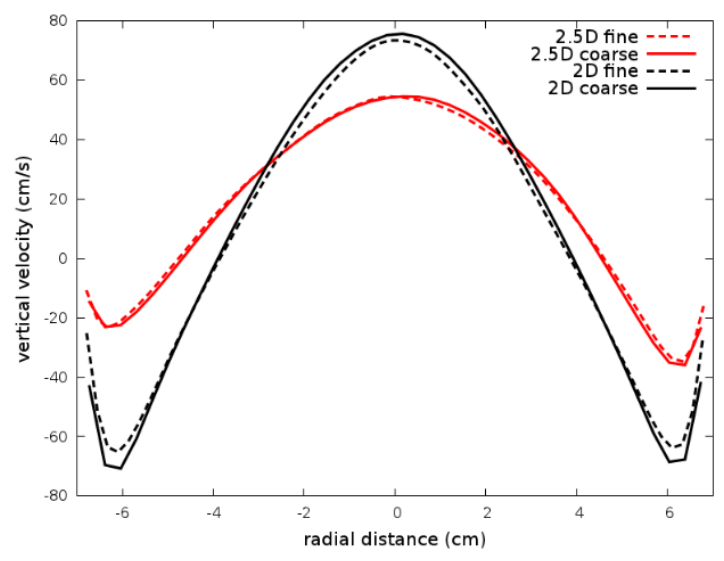

(b)

Figure 2. Time-averaged radial profiles averaged between $14.3-18.1 \mathrm{~cm}$ above the distributor predicted by coarse and fine grids (a) voidage, (b) vertical solid velocity ( $U g=80 \mathrm{~cm} / \mathrm{s}, \mathrm{d}_{\mathrm{p}}=350$ $\mu \mathrm{m})$. 


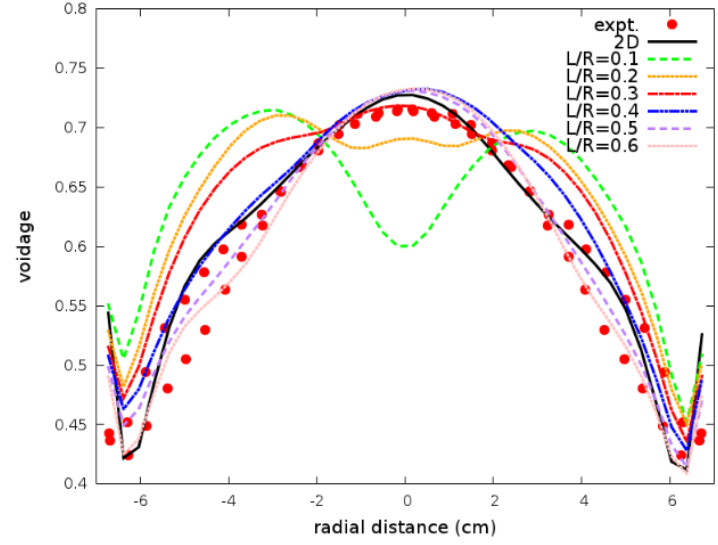

(a)

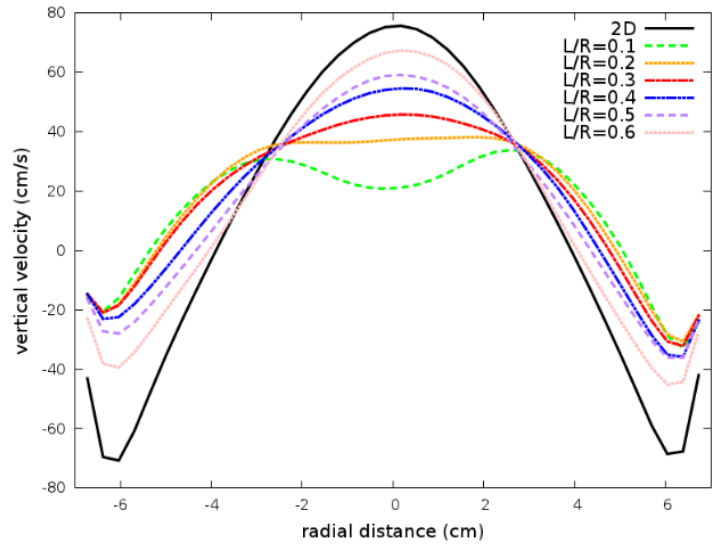

(b)

Figure 3. Time-averaged radial profiles averaged between $14.3-18.1 \mathrm{~cm}$ above the distributor predicted by different L/Rs, (a) voidage, (b) vertical solid velocity $\left(\mathrm{Ug}=80 \mathrm{~cm} / \mathrm{s}, \mathrm{d}_{\mathrm{p}}=350 \mu \mathrm{m}\right)$.
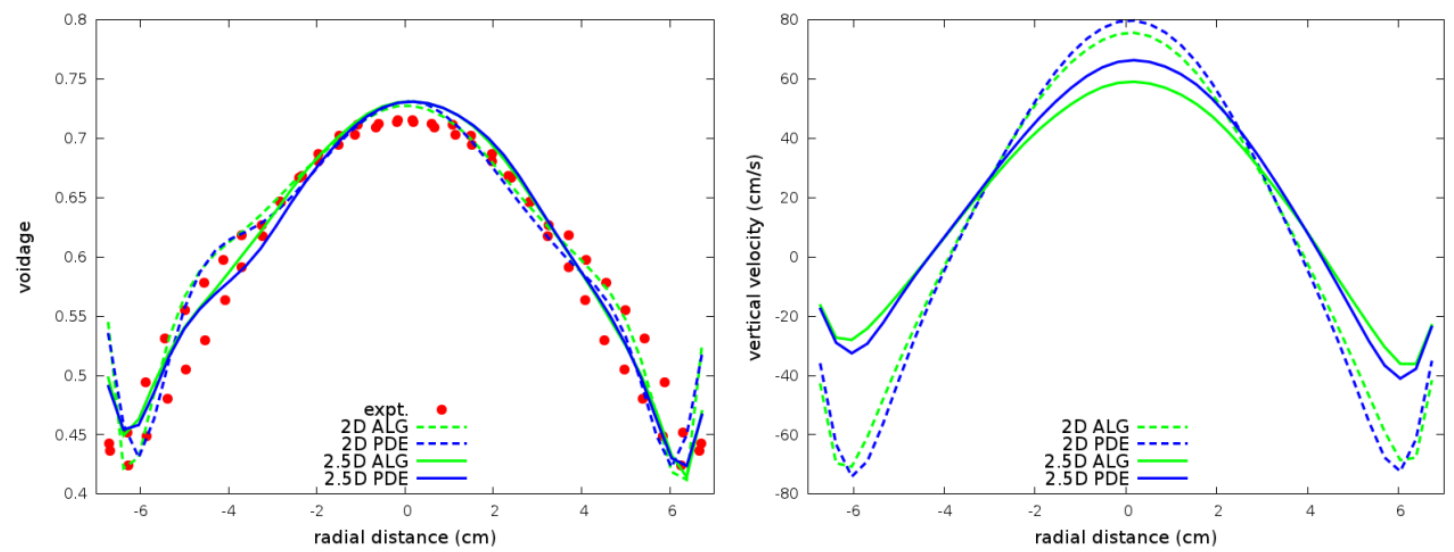

Figure 4. Time-averaged radial profiles averaged between 14.3-18.1 cm above the distributor predicted by algebraic and PDE granular temperature, (a) voidage, (b) vertical solid velocity (Ug $\left.=80 \mathrm{~cm} / \mathrm{s}, \mathrm{d}_{\mathrm{p}}=350 \mu \mathrm{m}\right)$. 


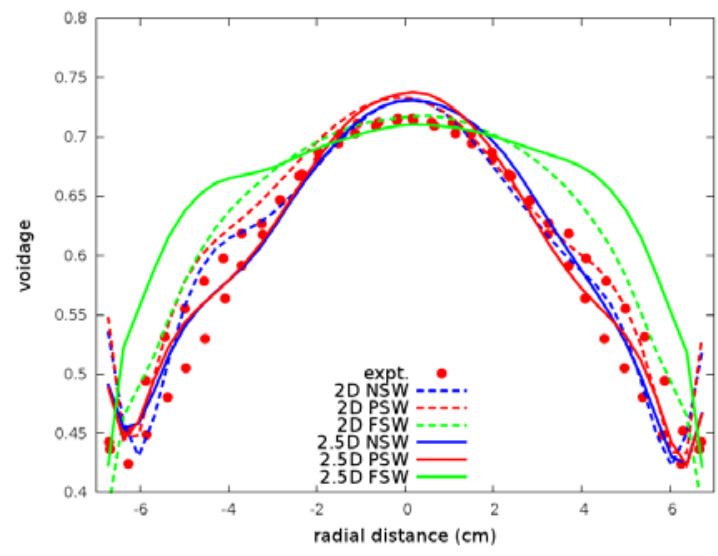

(a)

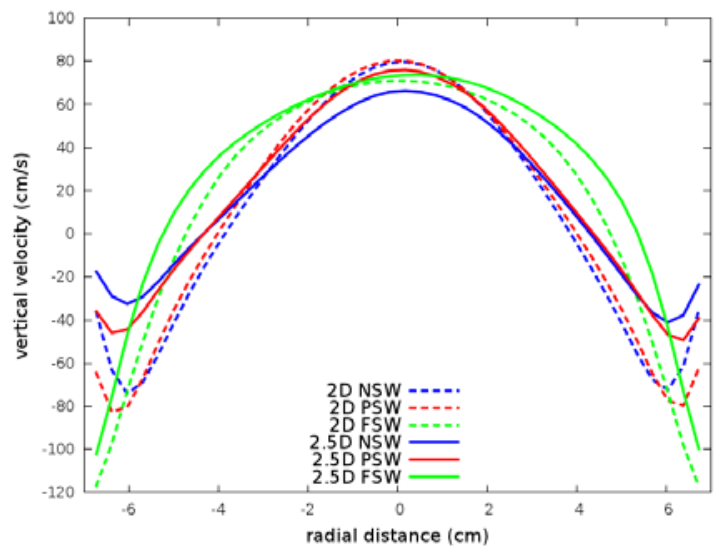

(b)

Figure 5. Time-averaged radial profiles averaged between $14.3-18.1 \mathrm{~cm}$ above the distributor predicted by different types of wall boundary conditions for the solid phase $\left(U g=80 \mathrm{~cm} / \mathrm{s}, \mathrm{d}_{\mathrm{p}}=\right.$ $350 \mu \mathrm{m})$.
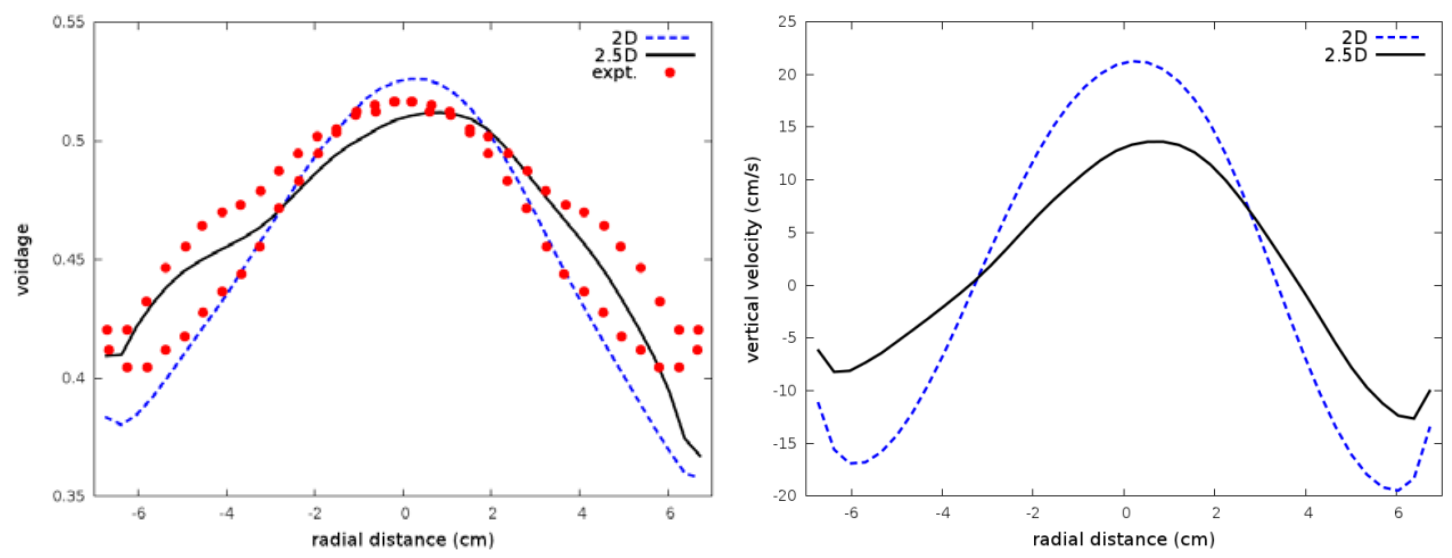

(a) 

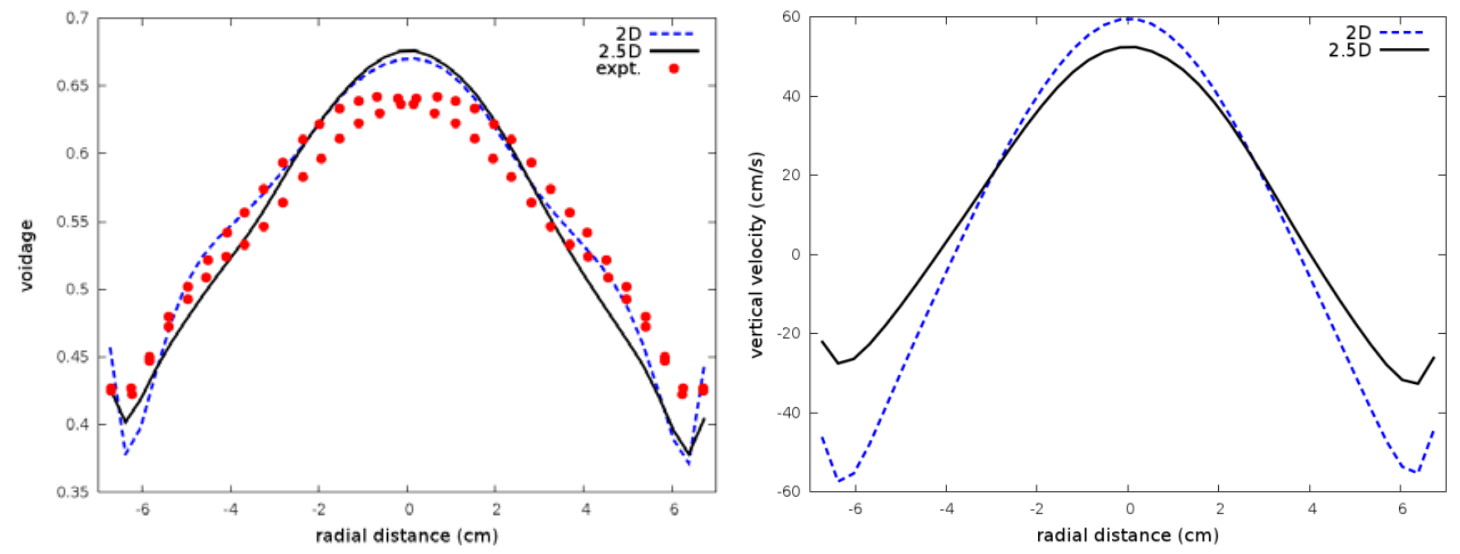

(b)
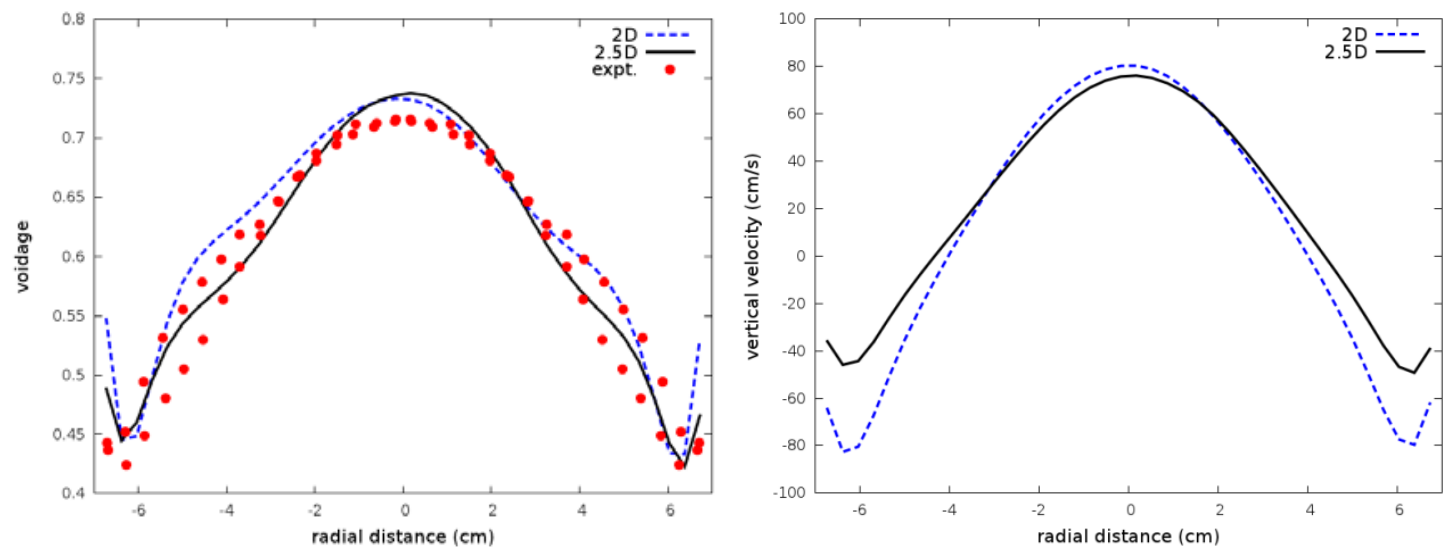

(c)

Figure 6. Time-averaged radial profiles averaged between $14.3-18.1 \mathrm{~cm}$ above the distributor for different superficial gas velocities, (a) $U g=26 \mathrm{~cm} / \mathrm{s}$, (b) $U g=54 \mathrm{~cm} / \mathrm{s}$, (c) $U g=80 \mathrm{~cm} / \mathrm{s}$. ( $d_{p}=$ $350 \mu \mathrm{m}$ ). 

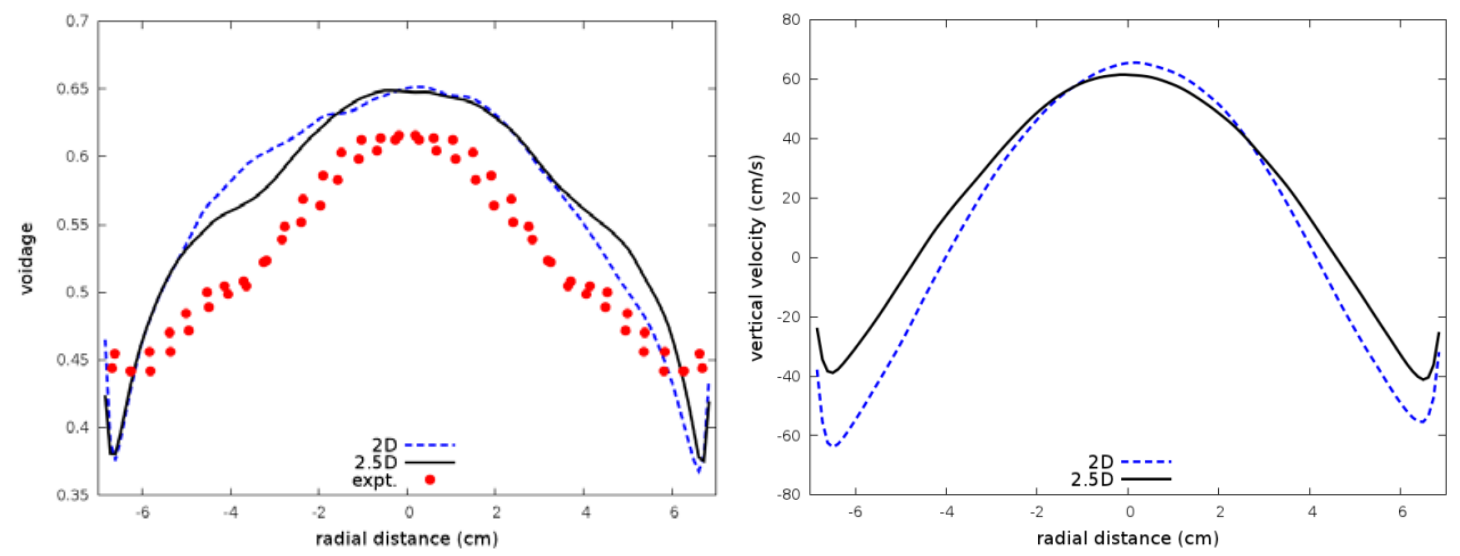

(a)
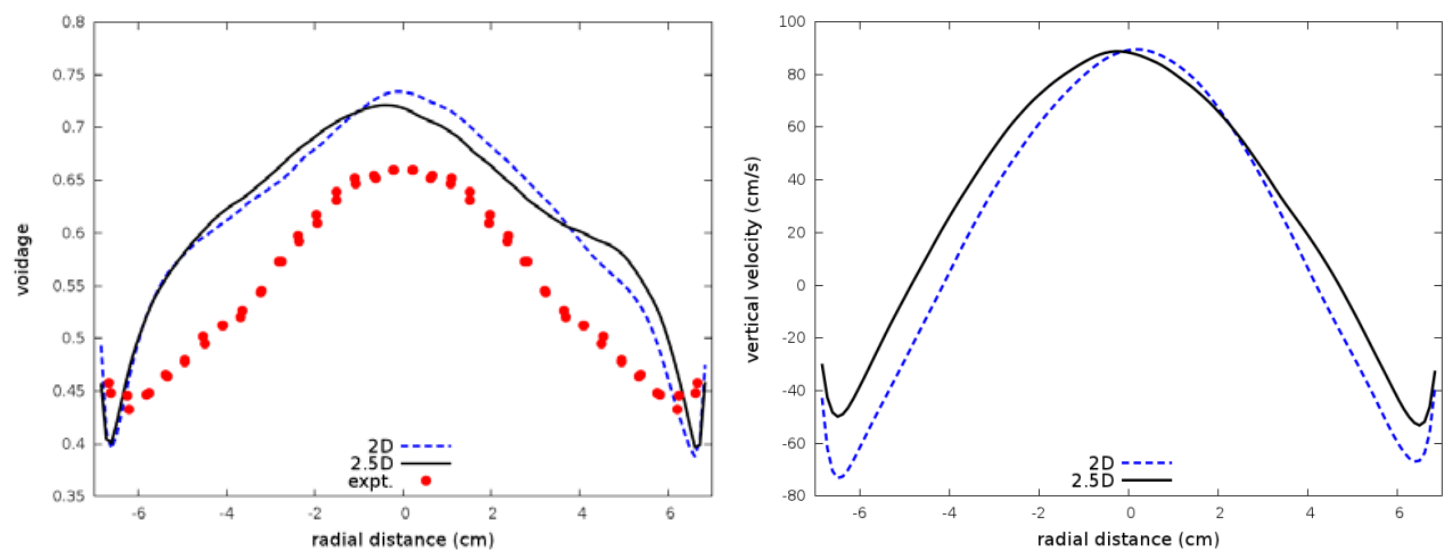

(b)

Figure 7. Time-averaged radial profiles averaged between $14.3-18.1 \mathrm{~cm}$ above the distributor for different superficial gas velocities, (a) $U g=26 \mathrm{~cm} / \mathrm{s}$, (b) $U g=40 \mathrm{~cm} / \mathrm{s}\left(\mathrm{d}_{\mathrm{p}}=125 \mu \mathrm{m}\right)$. 


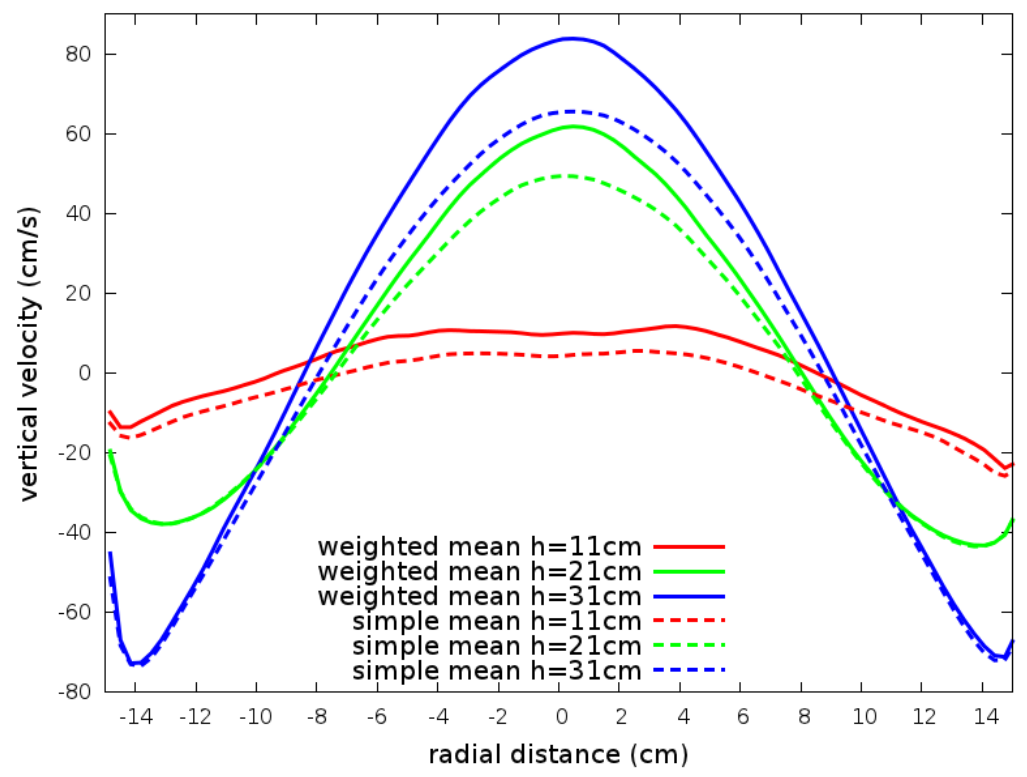

Figure 8. Comparison of mean solid vertical velocity calculated by weighted average and simple time average at different elevations ( $\mathrm{Ug}=3.5 \mathrm{Umf}$, Static bed height $=0.3 \mathrm{~m})$.
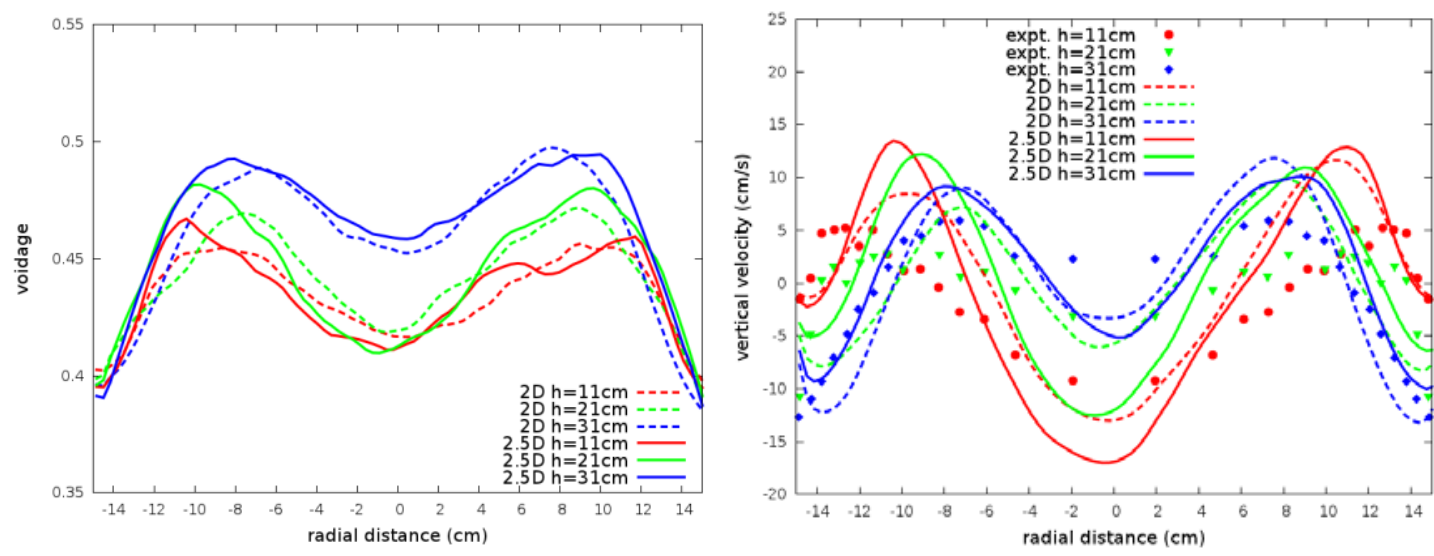

(a) 

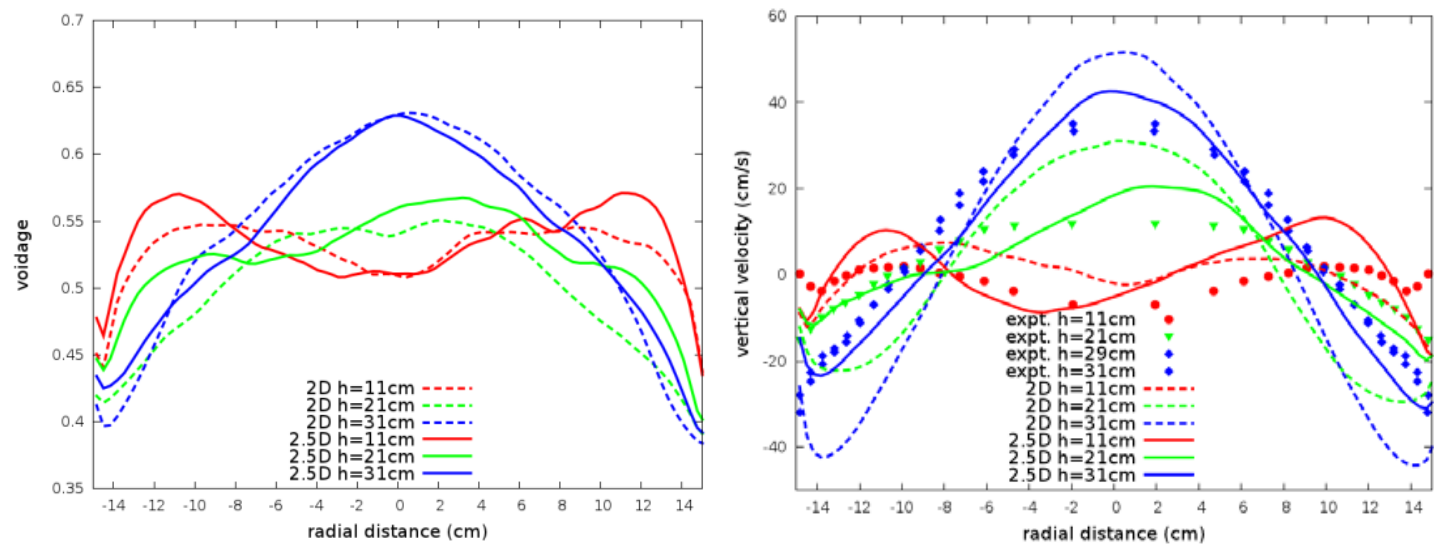

(b)
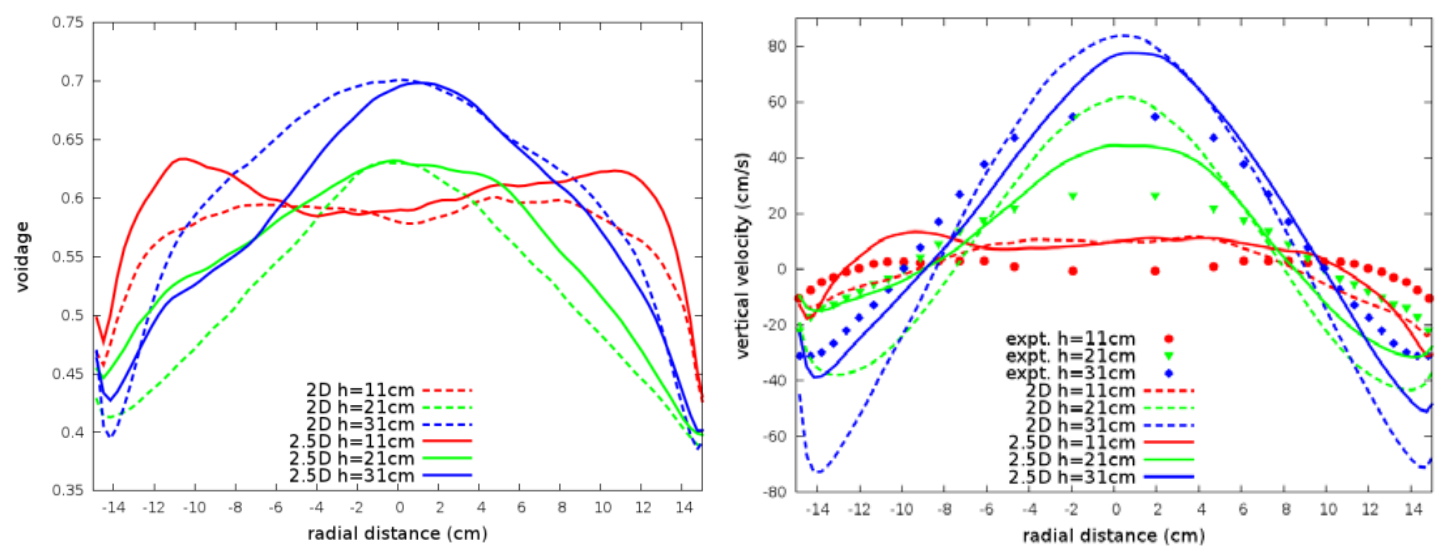

(c)

Figure 9. Radial profiles of solids velocity and voidage at different elevations (a) $\mathrm{Ug}=1.5 \mathrm{Umf}$, (b) $U g=2.5 U \mathrm{mf}$, (c) Ug = 3.5 Umf (Static bed height $=0.3 \mathrm{~m}$ )
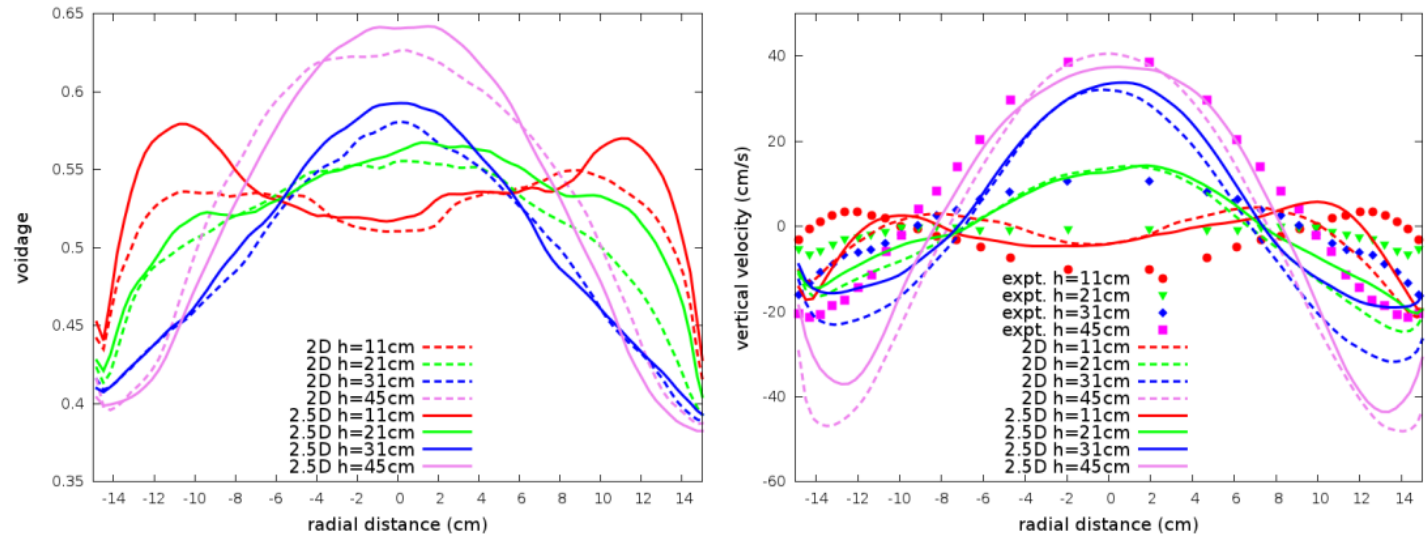

(a) 

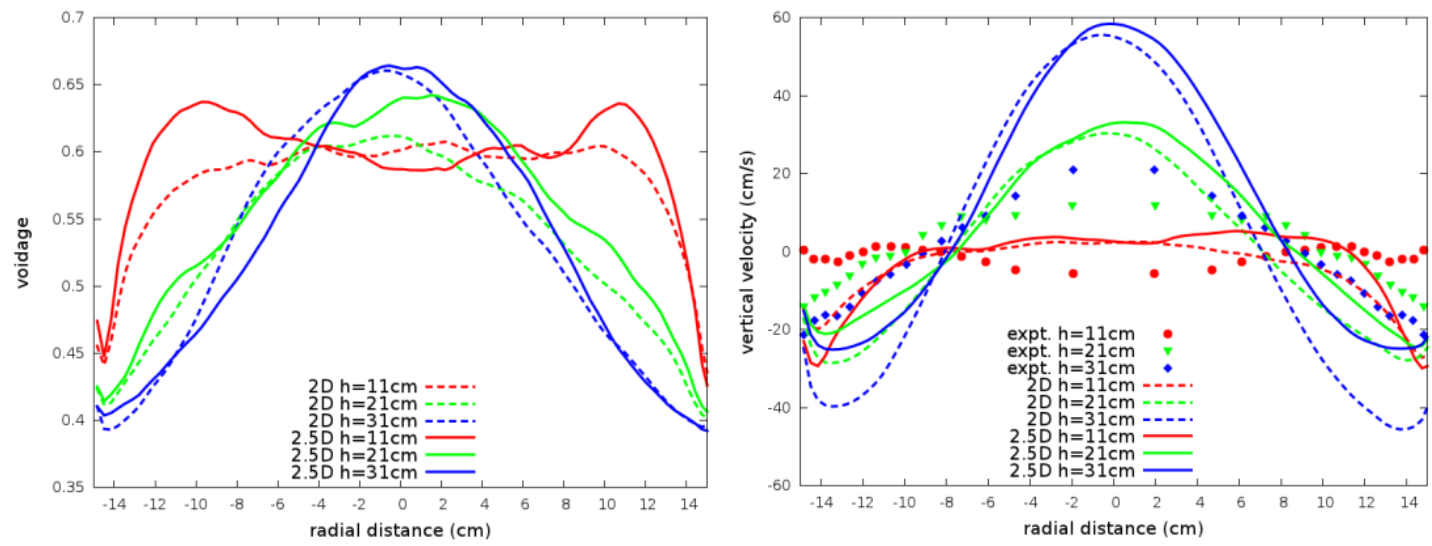

(b)

Figure 10. Radial profiles of solids velocity and voidage at different elevations (a) Ug $=2.5 \mathrm{Umf}$, (b) Ug = $3.5 \mathrm{Umf}$ (Static bed height $=0.45 \mathrm{~m}$ ). 